\title{
Cationic polymerization of $p$-methylstyrene using various metal chlorides: design rationale of initiating systems for controlled polymerization of styrenes
}

\author{
Ryohei Saitoh, Arihiro Kanazawa, Shokyoku Kanaoka and Sadahito Aoshima \\ Cationic polymerization of $p$-methylstyrene (pMeSt) was examined using various metal chlorides as Lewis acid catalysts in \\ dichloromethane. All of the catalysts used produced poly(pMeSt)s in the presence of 2,6-di-tert-butylpyridine (DTBP). However, \\ the polymerization behavior differed depending on the type of metal chloride. The polymerization reactions conducted using \\ $\mathrm{SnCl}_{4}$ and $\mathrm{ZnCl}_{2}$ proceeded in a controlled manner and yielded well-defined polymers, whereas metal trichlorides (for example, \\ $\mathrm{AlCl}_{3}, \mathrm{FeCl}_{3}$ and $\mathrm{GaCl}_{3}$ ) induced uncontrolled polymerization. In addition, the combination of $\mathrm{SnCl}_{4}$ and DTBP allowed the \\ controlled polymerization of styrene (St) and $p$-chlorostyrene ( $\mathrm{pClSt}$ ). Moreover, this initiating system was efficient for the \\ synthesis of star-shaped poly(pMeSt)s via the arm-first method through the addition of an alkylstyrene-type divinyl compound \\ used as a cross-linking agent.
}

Polymer Journal (2016) 48, 933-940; doi:10.1038/pj.2016.43; published online 18 May 2016

\section{INTRODUCTION}

Polystyrene and its derivatives $[$ poly(Sts)] are important polymeric materials for both industrial applications and fundamental research in polymer synthesis and physics. Poly(Sts) are widely synthesized through coordination, radical, anionic and cationic polymerization techniques. In cationic polymerization, Sts, except for alkoxystyrenes, are classified into less reactive monomers, compared with vinyl ethers (VEs) and $\mathrm{N}$-vinylcarbazole, because of the weak electron-donating character of the side chains. In addition, side reactions, such as Friedel-Crafts-type and $\beta$-proton elimination reactions, frequently occur because of the instability of growing carbocations. In several past studies, researchers have successfully suppressed such side reactions through the elaborate design of initiating systems using Lewis acid catalysts (for example, $\mathrm{BCl}_{3},{ }^{1} \mathrm{SnCl}_{4}{ }^{2-4}$ and $\mathrm{TiCl}_{4}{ }^{5-7}$ ) in conjunction with suitable additives, which demonstrates the controlled cationic polymerization of St. In addition, these initiating systems have been reported to be efficient for the controlled polymerization of substituted Sts, such as 2,4,6-trimethylstyrene, ${ }^{8}$ p-methylstyrene $(\mathrm{pMeSt})^{9-13}$ and $p$-chlorostyrene $(\mathrm{pClSt}){ }^{12-15}$

The design of initiating systems for controlled cationic polymerization is remedied by the careful choice of an appropriate catalyst and additive. Thus, the base-assisting living polymerization systems, which provide various combinations of metal chlorides and weak Lewis bases, are promising. ${ }^{12,13}$ Both the type of a catalyst and a base as well as the base concentration widen the availability of systems for controlled polymerization. Specifically, a large quantity of a weak Lewis base, such as an ester or ether, results in a living cationic polymerization of highly reactive monomers, such as alkyl VEs and alkoxystyrenes. In contrast, much lower concentrations of a weak Lewis base and/or a weaker Lewis base were demonstrated to be effective for the controlled cationic polymerization of less reactive St monomers. ${ }^{12,13,16,17}$ The limitations of initiating systems for the controlled cationic polymerization of St derivatives may include the narrower scope of effective Lewis acid catalysts compared to those of VEs. Metal trichlorides (for example, $\mathrm{AlCl}_{3}, \mathrm{FeCl}_{3}$ and $\mathrm{GaCl}_{3}$ ) that induce living polymerization of isobutyl VE (IBVE) ${ }^{18}$ were reported to be inefficient for the controlled polymerization of $p$-methoxystyrene (pMOS). ${ }^{19}$ This suggests that suitable reaction conditions must be designed depending on the reactivities and monomer types used in cationic polymerization.

In this study, we focused on pMeSt as a model monomer of a relatively low reactive St derivative. Cationic polymerization of pMeSt was conducted using metal chlorides to examine the polymerization behavior and the side reactions. As a result, the initiating system that consisted of $\mathrm{SnCl}_{4}$ and 2,6-di-tert-butylpyridine (DTBP) was demonstrated to be highly efficient for the controlled polymerization of pMeSt in dichloromethane. In addition, this initiating system was effective for the controlled polymerization of less reactive Sts, such as St and pClSt. Moreover, the star-shaped polymers of poly(pMeSt) arm chains were synthesized using an alkylstyrene-type divinyl compound as a cross-linking agent (Scheme 1).

\section{EXPERIMENTAL PROCEDURE}

\section{Materials}

p-Methylstyrene (pMeSt (TCI, Tokyo, Japan; >96\%)), p-methoxystyrene (pMOS (TCI; >95\%)), styrene (St (Wako, Osaka, Japan; 99\%)), 
Styrene and its derivatives<smiles>C=Cc1ccc(OC)cc1</smiles>
pMOS<smiles>C=Cc1ccc(C)cc1</smiles>

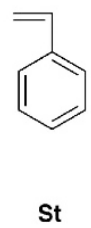

Metal chlorides<smiles>C=Cc1ccc(Cl)cc1</smiles>

\section{$\mathrm{SnCl}_{4} \mathrm{ZnCl}_{2}$}

$\begin{array}{llll}\mathrm{AlCl}_{3} & \mathrm{FeCl}_{3} & \mathrm{GaCl}_{3}\end{array}$

\section{Styrene-type divinyl compounds}

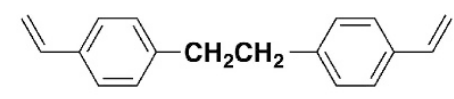

BVPE

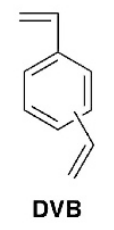

DVB
Initiators

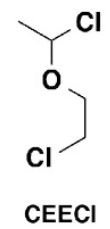

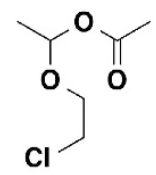

CEEA

Scheme 1 Structures of monomers, initiators, and catalysts used in this study.

p-chlorostyrene (pClSt (TCI; >98\%)), divinylbenzene (DVB; meta/para $=3 / 2$ (Nippon Steel \& Sumikin Chemical, Tokyo, Japan; 96\%)), p-chloromethylstyrene (pClMeSt (AGC Seimi Chemical, Kanagawa, Japan; >95\%)) and 2-chloroethyl vinyl ether (CEVE (TCI; 97\%)) were washed with 10\% aqueous sodium hydroxide solution and then with water. Then, the compounds were distilled once (for pClMeSt) or twice (except for pClMeSt) over calcium hydride under reduced pressure. Isobutyl vinyl ether (IBVE (TCI; 99\%)) was washed with $10 \%$ aqueous sodium hydroxide solution and then with water, and distilled twice over calcium hydride. Ethyl acetate (Nacalai Tesque, Kyoto, Japan; 99.5\%) was dried over molecular sieves $3 \mathrm{~A}$ and $4 \mathrm{~A}$, and distilled twice over calcium hydride. Tetrahydrofuran (Wako; $>99.5 \%$ ) was distilled over calcium hydride and then lithium aluminum hydride. For $n \mathrm{Bu}_{4} \mathrm{NCl}$, a stock solution in dichloromethane was prepared from anhydrous $n \mathrm{Bu}_{4} \mathrm{NCl}$ (Aldrich, St Louis, MO, USA; 99\%). 2,6-Di-tert-butylpyridine (DTBP (Aldrich; 97\%)) was distilled twice over calcium hydride under reduced pressure. Dichloromethane (Wako; 99\%), $n$-hexane (Wako; 96\%) and toluene (Wako; 99.5\%) were dried by passage through solvent purification columns (Glass Contour, PPT, Nashua, NH, USA). The adducts of VEs with $\mathrm{HCl}$ (1-(isobutoxy)ethyl chloride; IBECl and 1-(2-chloroethoxy)ethyl chloride; $\mathrm{CEECl}$ ) and acetic acid (1-(2-chloroethoxy)ethyl acetate; CEEA) were prepared from the addition reaction of corresponding VE monomers with $\mathrm{HCl}$ and acetic acid, respectively, according to the method reported in the literature. ${ }^{20,21}$ 1,2-Bis(4-vinylphenyl)ethane (BVPE) was prepared from the Wurtz coupling reaction of pClMeSt, as previously reported, ${ }^{22}$ and, subsequently, purified via recrystallization from $n$-hexane. The commercially available $\mathrm{SnCl}_{4}$ (Aldrich; $1.0 \mathrm{M}$ solution in heptane) and $\mathrm{EtAlCl}_{2}$ (Wako; $1.0 \mathrm{M}$ solution in hexane) were used without further purification. For the following metal chlorides, stock solutions were prepared: $\mathrm{GaCl}_{3}$ (Aldrich; 99.999\%; $200 \mathrm{~mm}$ in hexane), $\mathrm{AlCl}_{3}$ (Aldrich $99 \%$; $500 \mathrm{~mm}$ in ethyl acetate), $\mathrm{ZnCl}_{2}$ (Aldrich; 99.99\% $300 \mathrm{~mm}$ in toluene containing $1.3 \mathrm{M}$ ethyl acetate) and $\mathrm{FeCl}_{3}$ (Aldrich; $99.99 \% 200 \mathrm{~mm}$ in toluene containing $2.0 \mathrm{M}$ ethyl acetate). All reagents (except for dichloromethane, hexane, toluene and BVPE) were preserved in brown glass ampules under dry nitrogen in a freezer.

\section{Polymerization procedure}

The following is a typical homopolymerization procedure (using $\mathrm{SnCl}_{4}$ in conjunction with DTBP). A glass tube equipped with a three-way stopcock was dried using a heat gun (Ishizaki, Tokyo, Japan; PJ-206A; blow temperature $\sim 450^{\circ} \mathrm{C}$ ) under dry nitrogen for $\sim 10 \mathrm{~min}$. Dichloromethane $(3.8 \mathrm{ml})$, diluted DTBP solution in dichloromethane $\left(0.20 \mathrm{ml}, 1.0 \times 10^{-2} \mathrm{mmol}\right)$, pMeSt $(0.30 \mathrm{ml}, 2.3 \mathrm{mmol})$ and diluted $\mathrm{CEECl}$ solution in dichloromethane $\left(0.50 \mathrm{ml}, 2.0 \times 10^{-2} \mathrm{mmol}\right)$ were sequentially added in the stated order into the tube using dry syringes. The mixture in the glass tube was cooled to $0{ }^{\circ} \mathrm{C}$ in an ice bath. The reaction was started by the addition of a prechilled $\mathrm{SnCl}_{4}$ solution in dichloromethane/heptane $\left(7 / 1 \mathrm{v} / \mathrm{v} ; 0.20 \mathrm{ml} ; 2.5 \times 10^{-2} \mathrm{mmol}\right)$. After a predetermined reaction time $(16 \mathrm{~min})$, the polymerization was terminated with methanol $(3 \mathrm{ml})$ that contained a small amount of aqueous ammonia solution $(0.1 \%)$. The quenched reaction mixture was diluted in dichloromethane and was washed with a diluted hydrochloric acid, an aqueous $\mathrm{NaOH}$ solution, and water to remove the initiator residue. After the washing process, the solution was evaporated, and the residue was vacuum-dried for $2 \mathrm{~h}$ at $50^{\circ} \mathrm{C}$ and $2 \mathrm{~h}$ at $60^{\circ} \mathrm{C}$ to obtain a solid polymer $(0.23 \mathrm{~g})$. The monomer conversion was determined using gravimetry (conversion $=85 \%$; for some reactions, the monomer conversion was determined by gas chromatography using heptane as an external standard). The GPC analysis data were as follows: $M_{\mathrm{n}}=1.29 \times 10^{4}, M_{\mathrm{w}} / M_{\mathrm{n}}=1.12$.

The synthesis of a star-shaped poly(pMeSt) was performed as follows (the reaction using CEEA-EtAlCl$/ 2 / \mathrm{SnCl}_{4}$ in conjunction with BVPE as a cross-linking agent). A glass tube was dried in the same manner as the homopolymerization of pMeSt. Dichloromethane $(3.9 \mathrm{ml})$ and a mixture of CEEA and DTBP in dichloromethane $\left(0.40 \mathrm{ml}, 2.0 \times 10^{-2} \mathrm{mmol}\right.$ of CEEA and $1.0 \times 10^{-2} \mathrm{mmol}$ of DTBP) were added using dry syringes and mixed well. To the reaction mixture, $\mathrm{EtAlCl}_{2}$ solution in dichloromethane/hexane $(15 / 1 \mathrm{v} / \mathrm{v}$; $\left.0.20 \mathrm{ml}, 1.25 \times 10^{-2} \mathrm{mmol}\right)$ was added. The solution was kept at $0{ }^{\circ} \mathrm{C}$ for $\sim 10 \mathrm{~min}$. A prechilled $\mathrm{SnCl}_{4}$ solution in dichloromethane/heptane $(3 / 1 \mathrm{v} / \mathrm{v}$; $\left.0.20 \mathrm{ml} ; 5.0 \times 10^{-2} \mathrm{mmol}\right)$ and pMeSt $(0.30 \mathrm{ml}, 2.3 \mathrm{mmol})$ were sequentially added to start the arm polymerization. After a predetermined reaction time ( $15 \mathrm{~min})$, the cross-linking reaction was started by adding a BVPE solution in dichloromethane $(0.40 \mathrm{ml}, 0.40 \mathrm{mmol})$. After a predetermined interval, the reaction was quenched with methanol $(3 \mathrm{ml})$ containing a small amount of aqueous ammonia solution $(0.1 \%)$. The terminated reaction mixture was washed using the abovementioned method, and the product was dried under reduced pressure at room temperature.

\section{Characterization}

The molecular weight distribution (MWD) of the product polymer was measured using gel permeation chromatography (GPC) in chloroform as an eluent at $40{ }^{\circ} \mathrm{C}$ with polystyrene gel columns (Tosoh, Tokyo, Japan; TSKgel Multipore $\mathrm{H}_{\mathrm{XL}}-\mathrm{M} \times 3$ (exclusion limit $\mathrm{MW}=2 \times 10^{6}$; bead size $=5 \mu \mathrm{m}$; column size $=7.8 \mathrm{~mm}$ i.d. $\times 300 \mathrm{~mm}$ ) or TSKgel $\mathrm{GMH}_{\mathrm{HR}}-\mathrm{M} \times 3$ or 2 (exclusion limit $\mathrm{MW}=4 \times 10^{6}$; bead size $=5 \mu \mathrm{m}$; column size $=7.8 \mathrm{~mm}$ i.d $\times 300 \mathrm{~mm}$ ); flow rate $=1 \mathrm{ml} \mathrm{min}^{-1}$ ) that were connected to a Tosoh DP-8020 pump (Tosoh), a CO-8020 column oven (Tosoh), a UV-8020 ultraviolet detector (Tosoh) and an RI-8020 refractive-index detector (Tosoh). The number-average molecular weight $\left(M_{\mathrm{n}}\right)$ and polydispersity ratio (weight-average molecular weight/ number-average molecular weight $\left.\left(M_{\mathrm{w}} / M_{\mathrm{n}}\right)\right)$ were calculated from the chromatographs calibrated against 16 polystyrene standards (Tosoh; $M_{\mathrm{n}}=577-1.09 \times 10^{6} M_{\mathrm{w}} / M_{\mathrm{n}} \leqslant 1.1$ ). The refractive-index increment 
$(d n / d c)$ value was measured in chloroform using a differential spectrometer (Otsuka Electronics, Osaka, Japan; DRM-3000). The weight-average molecular weights $\left(M_{\mathrm{w}}\right)$ of star polymers were determined using GPC coupled with multiangle light scattering (GPC-MALS) in chloroform at $40^{\circ} \mathrm{C}$ on a DAWN HELEOS (Wyatt Technology, Santa Barbara, CA, USA; Ga-As laser, $\lambda=690 \mathrm{~nm}$ ). Nuclear magnetic resonance (NMR) spectra were recorded using a JEOL JNM-ECA 500 spectrometer (JEOL, Tokyo, Japan; $500.16 \mathrm{MHz}$ for ${ }^{1} \mathrm{H}$ ).

\section{RESULTS AND DISCUSSION}

Cationic polymerization of pMeSt in dichloromethane

The cationic polymerization of pMeSt catalyzed by various metal chlorides was examined in conjunction with an adduct of CEVE with $\mathrm{HCl}(\mathrm{CEECl})$ as a cationogen in the absence or presence of a weak Lewis base additive (DTBP and/or ethyl acetate) in dichloromethane (Scheme 2). Polymerization proceeded with the use of any of the investigated catalysts. However, the polymerization behavior critically depended on the catalyst and additives. Among the employed Lewis acid catalysts, $\mathrm{SnCl}_{4}$ and $\mathrm{ZnCl}_{2}$ provided superior controllability. The polymerization using $\mathrm{SnCl}_{4}$ or $\mathrm{ZnCl}_{2}$ in the presence of a small amount of DTBP proceeded in a controlled manner (entries 1 and 7 in Table 1; circle and triangle symbols in Figure 1). The $M_{\mathrm{n}}$ values of product polymers increased approximately in accordance with the calculated values, and the MWDs were relatively narrow throughout the polymerization process (Figures $1 \mathrm{~b}$ and $\mathrm{c}$ ). In addition, polymerization using $\mathrm{SnCl}_{4}$ proceeded in a controlled manner even at $-78^{\circ} \mathrm{C}$ in the presence of DTBP (entry 3 ).

The use of a suitable additive was demonstrated to be indispensable for controlled cationic polymerization reactions. The reaction using

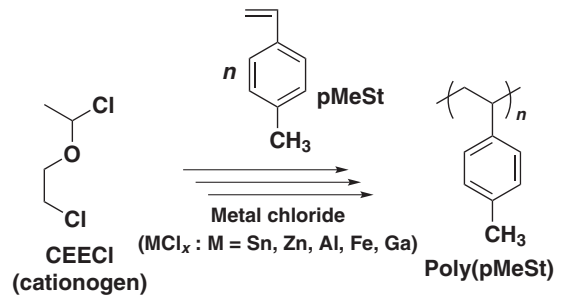

Scheme 2 Cationic polymerization of pMeSt.
$\mathrm{SnCl}_{4}$ or $\mathrm{ZnCl}_{2}$ in the absence of DTBP resulted in uncontrolled polymerization (entries 2 and 8), yielding poly(pMeSt)s with bimodal MWDs (Supplementary Figure S1). By contrast, polymerization was completely suppressed when an equimolar amount of DTBP relative to the amount of $\mathrm{SnCl}_{4}$ was used (entry 4). In addition, the use of ethyl acetate, which is a weak Lewis base very effective for living polymerization of alkyl VEs and pMOS, resulted in a less controlled reaction. Polymerization in the presence of a large amount of ethyl acetate yielded a product polymer with an $M_{\mathrm{n}}$ value smaller than the theoretical value (entry 5 ).

Unlike tetra- and dichlorides, metal trichlorides- $\mathrm{AlCl}_{3}, \mathrm{FeCl}_{3}$ and $\mathrm{GaCl}_{3}$-were ineffective in controlling pMeSt polymerization. The reactions involving these catalysts produced polymers with uncontrolled MWs and broad MWDs. The products obtained using $\mathrm{AlCl}_{3}$ had MWs substantially greater than the theoretical values, irrespective of monomer conversion (entry 9; double-triangles in Figure 1), most likely because of low initiation efficiency. The reactions with $\mathrm{FeCl}_{3}$ and $\mathrm{GaCl}_{3}$ proceeded instantaneously in uncontrolled manners, producing polymers with broad MWDs (entries 11 and 13; squares and inverted triangles in Figure 1). In addition, polymerization using $\mathrm{AlCl}_{3}$ or $\mathrm{FeCl}_{3}$ in the absence of DTBP (entries 10 and 12) exhibited behaviors similar to those in the presence of DTBP. Moreover, $\mathrm{GaCl}_{3}$ induced very fast polymerization, which yielded ill-defined products even at low temperature (entry 14) or in the presence of a larger amount of DTBP (entry 15).

${ }^{1} \mathrm{H} \mathrm{NMR}$ analysis of the poly(pMeSt)s obtained using $\mathrm{SnCl}_{4}, \mathrm{ZnCl}_{2}$, $\mathrm{FeCl}_{3}$ or $\mathrm{GaCl}_{3}$ in the presence of DTBP was conducted to investigate the side reactions that occurred during polymerization (Figure 2). The spectra of products obtained with $\mathrm{SnCl}_{4}$ or $\mathrm{ZnCl}_{2}$ exhibited peaks assignable to the microstructures with the $\alpha$-end derived from CEECl and the $\omega$-end with a carbon-chlorine bond. ${ }^{9}$ No peaks assigned to the structures derived from side reactions, such as $\beta$-proton elimination reactions and Friedel-Crafts-type reactions, were observed in the spectra. The $M_{\mathrm{n}}$ values calculated on the basis of integral ratios of the methyl group peak at the $\alpha$-end (peak $a$ ) and of the phenyl protons peaks at the side chains (peak $i$ ) were close to those determined by GPC using polystyrene calibration $\left[M_{\mathrm{n}}(\mathrm{NMR})=9.2 \times\right.$ $10^{3}$ and $M_{\mathrm{n}}(\mathrm{GPC})=8.8 \times 10^{3}$ for $\mathrm{SnCl}_{4}, M_{\mathrm{n}}(\mathrm{NMR})=12.5 \times 10^{3}$ and

Table 1 Cationic polymerization of pMeSt with various metal chlorides in dichloromethane ${ }^{a}$

\begin{tabular}{|c|c|c|c|c|c|c|c|c|c|}
\hline Entry & $M C I_{\mathrm{x}}$ & {$[D T B P](\mathrm{mm})$} & {$[E t O A c](m m)$} & Temp. $\left({ }^{\circ} \mathrm{C}\right)$ & Time & Conv. (\%) & $M_{n} \times 10^{-3}(\mathrm{calcd})$ & $M_{n} \times 10^{-3}(o b s d)^{b}$ & $M_{w} / M_{n}^{\mathrm{b}}$ \\
\hline 1 & $\mathrm{SnCl}_{4}$ & 2.0 & 0 & 0 & $16 \mathrm{~min}$ & 85 & 11.6 & 12.9 & 1.12 \\
\hline 2 & & 0 & 0 & 0 & $40 \mathrm{~s}$ & 64 & 8.7 & 9.1 & 3.22 \\
\hline 3 & & 2.0 & 0 & -78 & $4 \mathrm{~h}$ & 97 & 13.2 & 12.7 & 1.21 \\
\hline 4 & & 5.0 & 0 & 0 & $43 \mathrm{~h}$ & 2 & - & - & - \\
\hline 5 & & 0 & 1000 & 0 & $8 \mathrm{~h}$ & 78 & 10.6 & 6.5 & 1.41 \\
\hline $6^{c}$ & & 2.0 & 0 & 0 & $15 \mathrm{~min}$ & 98 & 13.3 & 11.2 & 1.21 \\
\hline 7 & $\mathrm{ZnCl}_{2}$ & 2.0 & $20^{d}$ & 0 & $21 \mathrm{~h}$ & 96 & 13.1 & 13.0 & 1.29 \\
\hline 8 & & 0 & $20^{d}$ & 0 & $1.5 \mathrm{~min}$ & 95 & 10.9 & 12.9 & 9.55 \\
\hline 9 & $\mathrm{AlCl}_{3}$ & 2.0 & $100^{d}$ & 0 & $50 \mathrm{~min}$ & 92 & 12.5 & 32.0 & 2.94 \\
\hline 10 & & 0 & $100^{d}$ & 0 & $5 s$ & 13 & 1.8 & 67.0 & 2.24 \\
\hline 11 & $\mathrm{FeCl}_{3}$ & 2.0 & $50^{d}$ & 0 & $5 s$ & 92 & 12.5 & 11.7 & 2.18 \\
\hline 12 & & 0 & $50^{d}$ & 0 & $7 \mathrm{~s}$ & 100 & 13.6 & 9.8 & 4.38 \\
\hline 13 & $\mathrm{GaCl}_{3}$ & 2.0 & 0 & 0 & $1 \mathrm{~s}$ & 92 & 12.5 & 5.8 & 3.20 \\
\hline 14 & & 2.0 & 0 & -78 & $1 \mathrm{~s}$ & 78 & 10.6 & 20.3 & 2.95 \\
\hline 15 & & 5.0 & 0 & 0 & $5 s$ & 44 & 6.0 & 4.1 & 2.92 \\
\hline
\end{tabular}

$\left.{ }_{\mathrm{apMeSt}}\right]_{0}=0.46 \mathrm{~m},[\mathrm{CEECl}]_{0}=4.0 \mathrm{~mm}$, [metal chloride $]_{0}=5.0 \mathrm{~mm}$ (except for entries 5 and 6 ) or $10 \mathrm{~mm}$ (for entries 5 and 6 ), $[\mathrm{DTBP}]=0-5.0 \mathrm{~mm},[\mathrm{EtOAc}]=0-1.0 \mathrm{~m} \mathrm{in} \mathrm{CH} \mathrm{Cl}_{2}$ at $0{ }^{\circ} \mathrm{C}$.

betermined by GPC (polystyrene standard).

${ }^{C} \mathrm{~A}$ combination of CEEA and $\mathrm{EtAICl}_{2}$ ( 4.0 and $2.5 \mathrm{~mm}$, respectively) was employed instead of CEECl.

${ }^{\mathrm{d}}$ Containing ethyl acetate derived from metal chloride stock solutions. 
a

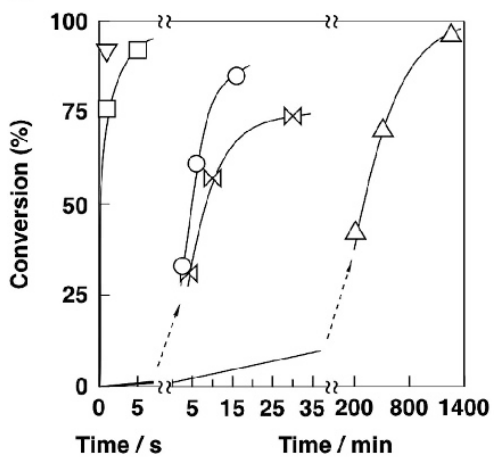

b

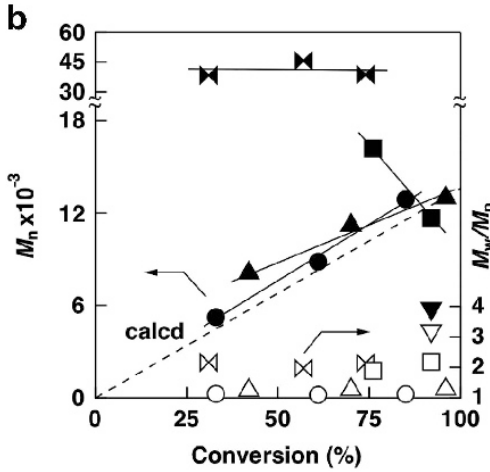

C

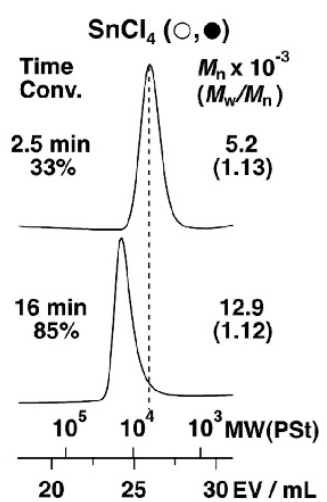

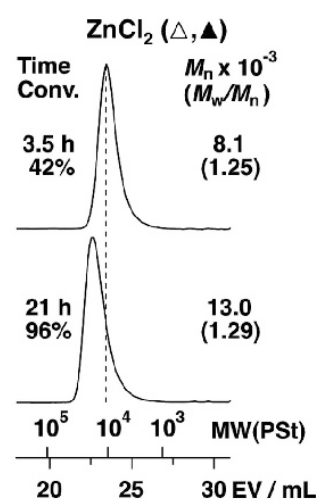

$\mathrm{FeCl}_{3}(\square, \boldsymbol{\square})$

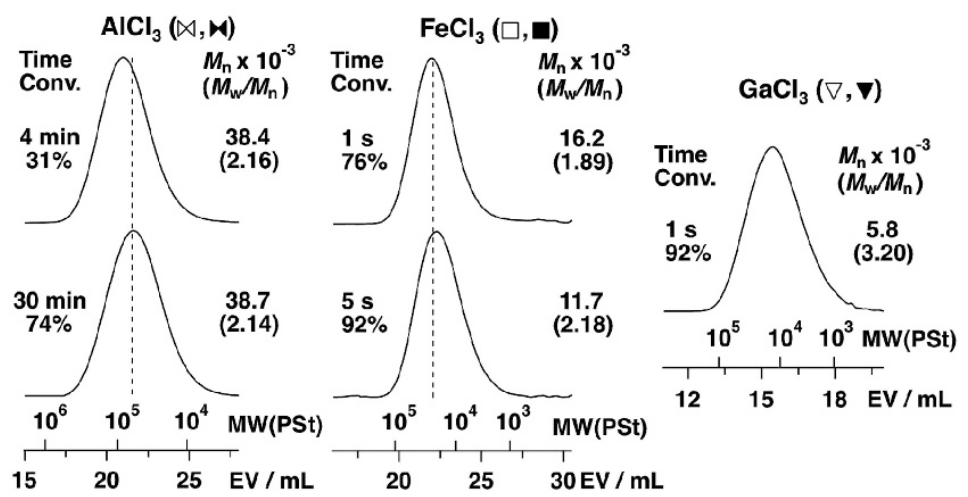

Figure 1 (a) Time-conversion curves, (b) $M_{\mathrm{n}}$ and $M_{\mathrm{w}} / M_{\mathrm{n}}$ for the polymerization of pMeSt and (c) MWD curves for poly(pMeSt)s obtained using SnCl, $\mathrm{ZnCl}_{2}, \mathrm{AlCl}_{3}, \mathrm{FeCl}_{3}$ and $\mathrm{GaCl}_{3}\left([\mathrm{pMeSt}]_{0}=0.46 \mathrm{~m},[\mathrm{CEECl}]_{0}=4.0 \mathrm{~mm} \text {, [metal chloride }\right]_{0}=5.0 \mathrm{~mm},[\mathrm{DTBP}]=2.0 \mathrm{~mm},[\mathrm{EtOAc}]=20 \mathrm{~mm}($ for ZnCl 2$), 50 \mathrm{~mm}$ (for $\mathrm{FeCl}_{3}$ ) or $100 \mathrm{~mm}$ (for $\mathrm{AlCl}_{3}$ ) in $\mathrm{CH}_{2} \mathrm{Cl}_{2}$ at $0{ }^{\circ} \mathrm{C}$ ). Symbol: circle for $\mathrm{SnCl}_{4}$, triangle for $\mathrm{ZnCl}_{2}$, double-triangle for $\mathrm{AlCl}_{3}$, square for $\mathrm{FeCl}_{3}$ and inverted triangle for $\mathrm{GaCl}_{3}$.

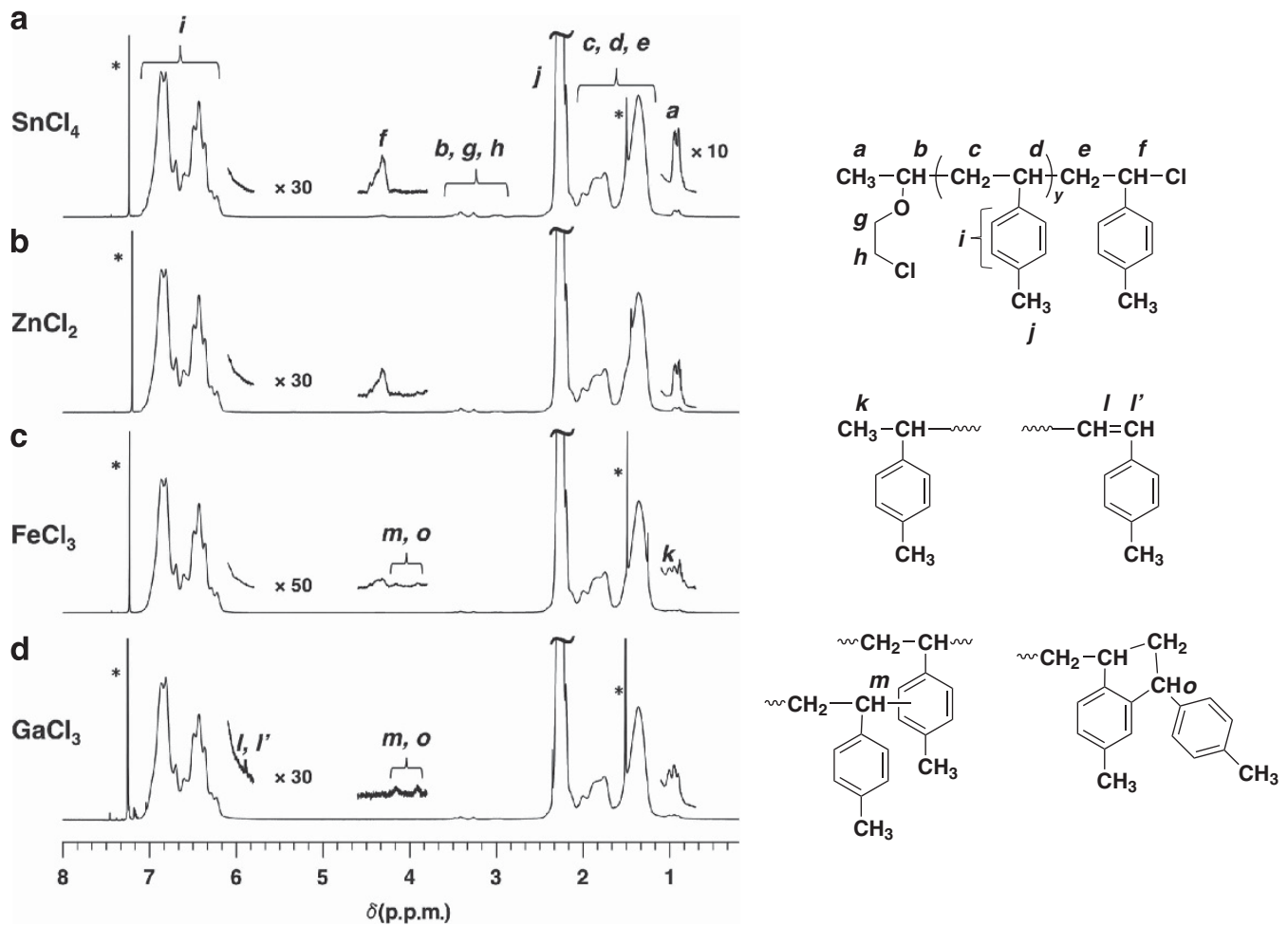

Figure $2{ }^{1} \mathrm{H}$ NMR spectra of poly(pMeSt)s obtained using (a) $\mathrm{SnCl}_{4}$ [Conv. $=61 \%, M_{\mathrm{n}}=8.8 \times 10^{3}, M_{\mathrm{w}} / M_{\mathrm{n}}=1.10$ ], (b) $\mathrm{ZnCl}_{2}\left[\mathrm{Conv} .=70 \%, M_{\mathrm{n}}=11.2 \times 10^{3}\right.$, $M_{\mathrm{w}} / M_{\mathrm{n}}=1.27$ ], (c) $\mathrm{FeCl}_{3}$ [Conv. $=76 \%, M_{n}=16.2 \times 10^{3}, M_{\mathrm{w}} / M_{\mathrm{n}}=1.89$ ] and (d) $\mathrm{GaCl}_{3}$ [Conv. $=92 \%, M_{\mathrm{n}}=5.8 \times 10^{3}, M_{\mathrm{w}} / M_{\mathrm{n}}=3.20$ ] (see Figure 1 for the polymerization conditions). ${ }^{*} \mathrm{CHCl}_{3}$, water. 
$M_{\mathrm{n}}(\mathrm{GPC})=11.2 \times 10^{3}$ for $\left.\mathrm{ZnCl}_{2}\right]$. Thus, these results demonstrate that polymerization reactions using $\mathrm{SnCl}_{4}$ or $\mathrm{ZnCl}_{2}$ proceeded in a highly controlled manner. However, the peaks assigned to the structures derived from side reactions were observed in the spectra of product polymers obtained using $\mathrm{FeCl}_{3}$ and $\mathrm{GaCl}_{3}$. The peaks at 3.8-4.2 p.p.m. (peaks $m$ and $o$ ) 23 and 5.9 p.p.m. (peaks $l$ and $\left.l^{\prime}\right)^{24}$ were assigned to the structure resulting from the intra- and/or intermolecular FriedelCrafts reactions and $\beta$-proton elimination reaction, respectively. These side reactions liberated protons, which induced transfer reactions to generate new propagating chains. In fact, the peak at 1.0 p.p.m. (peak $k$ ), which is assigned to the methyl group derived from the addition reaction of a proton to pMeSt, suggests the generation of proton-initiated polymer chains. In addition, the results indicate that the addition of DTBP, which is a reagent that is often employed as a proton trap reagent in cationic polymerization reactions, did not suppress such transfer reactions mediated by protons in the present system.

The difference among metal chlorides in the polymerization of pMeSt demonstrated the trends similar to those in the polymerization of pMOS, ${ }^{19}$ although different mechanisms appeared to operate in these reactions. Lewis acids with two coordination sites, such as di- and tetrachlorides, effectively controlled the polymerization of pMOS. This suggests the generation of counteranions that coordinate a weak Lewis base. However, in the pMeSt case, DTBP (an additive that does not coordinate to metal halides ${ }^{25}$ ) was effective for controlled polymerization. To examine the interaction between metal chlorides and DTBP, we performed ${ }^{1} \mathrm{H}$ NMR analysis (Table 2). The peaks of DTBP in the mixture of $\mathrm{SnCl}_{4}$ and DTBP exhibited downfield shifts compared to the peaks of free DTBP. Interestingly, the mixtures of DTBP with $\mathrm{SnCl}_{4}$ and $n \mathrm{Bu}_{4} \mathrm{NCl}$, which generate less acidic species, $\mathrm{SnCl}_{5}{ }^{-26}$ or with $\mathrm{GaCl}_{3}$ also exhibited almost the same chemical shift values. These results suggest that no direct interactions occur between DTBP and Lewis acids and that the same species, such as protonated DTBP $\left(\mathrm{H}^{+}-\mathrm{DTBP}\right)$, were generated via the reaction with adventitious water and Lewis acids ${ }^{25}$ in all of the mixtures.

Some anionic species, such as $\mathrm{SnCl}_{4} \mathrm{X}^{-}(\mathrm{X}=\mathrm{Cl}$ or $\mathrm{OH})$, are likely responsible for the control over $\mathrm{pMeSt}$ polymerizations via the 'common-ion effect'. A previous study have reported that the controlled polymerization of pMeSt with $\mathrm{SnCl}_{4}$ in the presence of $n \mathrm{Bu}_{4} \mathrm{NCl}^{9}$ proceeds via the generation of $\mathrm{SnCl}_{5}{ }^{-}$, a species that adjusts the dormant-active equilibrium. The reaction using DTBP probably proceeded via a mechanism similar to the previous system using the added salt. In fact, Storey et al. ${ }^{25}$ proposed that the controlled polymerization of isobutene using $\mathrm{TiCl}_{4}$ in conjunction with DTBP

Table $2{ }^{1} \mathrm{H}$ NMR chemical shifts of DTBP in mixtures with metal chloride or metal chloride $/ \mathrm{Bu}_{4} \mathrm{NCl}^{\mathrm{a}}$

\begin{tabular}{|c|c|c|c|}
\hline \multirow[b]{2}{*}{ Solute (mм) } & \multicolumn{3}{|c|}{ Chemical shift in p.p.m. } \\
\hline & $\begin{array}{l}\text { 4-position on the } \\
\text { ring }\end{array}$ & $\begin{array}{c}\text { 3-and 5-positions on } \\
\text { the ring }\end{array}$ & ${ }^{t} B u$-group \\
\hline DTBP (60) & 7.53 & 7.11 & 1.36 \\
\hline DTBP/SnCl $4(10 / 20)$ & 8.58 & 7.91 & 1.59 \\
\hline $\begin{array}{l}\text { DTBP/SnCl } / 4 / n \mathrm{Bu}_{4} \mathrm{NCl} \\
(10 / 20 / 20)\end{array}$ & 8.59 & 7.91 & 1.59 \\
\hline DTBP/GaCl $3(10 / 20)$ & 8.57 & 7.91 & 1.60 \\
\hline
\end{tabular}

asolvents: in $\mathrm{CD}_{2} \mathrm{Cl}_{2}, \mathrm{CD}_{2} \mathrm{Cl}_{2} / \mathrm{CH}_{2} \mathrm{Cl}_{2} /$ heptane (44/5/1 v/v/v), $\mathrm{CD}_{2} \mathrm{Cl}_{2} / \mathrm{CH}_{2} \mathrm{Cl}_{2} /$ heptane (42/7/1 $\mathrm{v} / \mathrm{v} / \mathrm{v})$ and $\mathrm{CD}_{2} \mathrm{Cl}_{2} / \mathrm{CH}_{2} \mathrm{Cl}_{2} /$ hexane $(8 / 1 / 1 \mathrm{v} / \mathrm{v} / \mathrm{v})$ from top to bottom, respectively; recorded at $25^{\circ} \mathrm{C}$. See Supplementary Figure S2 in the Supplementary information for the spectra. resulted from the formation of anions, such as $\mathrm{TiCl}_{5}^{-}$, through the reaction of DTBP, adventitious water and $\mathrm{TiCl}_{4}$. Similar mechanisms are considered to operate in the polymerization of pMeSt using $\mathrm{SnCl}_{4}$ and DTBP to induce controlled reactions. However, the polymerization using equimolar amounts of $\mathrm{SnCl}_{4}$ and DTBP did not proceed (entry 4 in Table 1 ). This is possibly attributed to the generation of a large amount of $\mathrm{SnCl}_{4}(\mathrm{OH})^{-}$and/or the undetectable interaction between $\mathrm{SnCl}_{4}$ and DTBP. ${ }^{27-31}$ In contrast, metal trichlorides were ineffective in the present system, corresponding to the ineffectiveness of the anion effect in the cationic polymerization of $\mathrm{St}^{32}$ and $\mathrm{IBVE}^{18,33}$ using $\mathrm{EtAlCl}_{2}, \mathrm{FeCl}_{3}$ and $\mathrm{GaCl}_{3}$ in conjunction with $n \mathrm{Bu}_{4} \mathrm{NCl}$.

\section{Cationic polymerization of St and its derivatives}

The cationic polymerizations of St and its derivatives that were less reactive than pMeSt were also observed to be controlled through the use of initiating systems composed of $\mathrm{SnCl}_{4}$ and DTBP. Polymerizations of pClSt and St smoothly proceeded under conditions similar to those under which the polymerization of pMeSt proceeded, yielding polymers with unimodal MWDs (Figures $3 \mathrm{~b}$ and $\mathrm{c}$ ). In particular, the polymerization of pClSt was highly controlled and produced polymers with $M_{\mathrm{n}}$ values that increased in direct proportion to the monomer conversion rate. Moreover, the $M_{\mathrm{n}}$ values calculated from the integral ratios of the peaks for the phenyl rings and the $\alpha$-end in the ${ }^{1} \mathrm{H}$ NMR spectrum strongly agree with the theoretical values $\left[M_{\mathrm{n}}(\right.$ calcd $)=8.8 \times 10^{3}$ and $\left.M_{\mathrm{n}}(\mathrm{NMR})=8.8 \times 10^{3}\right]$. However, the obtained $\operatorname{poly}(\mathrm{St}) \mathrm{s}$ had $M_{\mathrm{n}}$ values lower than the theoretical values $\left[M_{\mathrm{n}}(\right.$ calcd $)=12.3 \times 10^{3}$ and $\left.M_{\mathrm{n}}(\mathrm{GPC})=6.7 \times 10^{3}\right]$. In addition, an obvious tailing appeared at the lower MW region of the MWD curve (Figure $3 \mathrm{c}$, lower). These results suggest that transfer reactions occurred at the latter stage of polymerization. In fact, the ${ }^{1} \mathrm{H}$ NMR spectrum of the product showed peaks at 4.0, 5.2 and 5.7 p.p.m. that indicated the occurrence of Friedel-Crafts-type reactions between the phenyl ring of a St monomer and the propagating chain (Supplementary Figure S3). The peak of an $\alpha$-end generated from a proton as a result of such transfer reactions was also observed in the ${ }^{1} \mathrm{H}$ NMR spectrum. Unlike the reactions of pMeSt, St and pClSt, however, the polymerization of pMOS using $\mathrm{SnCl}_{4}$ in conjunction with DTBP was completely uncontrolled and produced a high-MW polymer with a broad MWD (Figure 3d). In addition, the polymerization was complete in $5 \mathrm{~s}$, which indicated that a very active reaction occurred under the employed conditions. Even in the presence of an excess amount of DTBP $\left(\left[\mathrm{SnCl}_{4}\right]_{0} /[\mathrm{DTBP}]=5.0 / 6.0 \mathrm{~mm}\right)$, the controlled polymerization of pMOS did not proceed ( conversion $=35 \%$ in $5 \mathrm{~s}, M_{\mathrm{n}}=16.2 \times 10^{3}, M_{\mathrm{w}} / M_{\mathrm{n}}=1.75$ ).

Suitable additives for the polymerizations of these St derivatives are considered to rely greatly on monomer reactivity. The order of reactivity is as follows: pMOS $\gg$ pMeSt $>$ St $>$ pClSt. ${ }^{17}$ (The apparent polymerization rate constants $\left(k_{\mathrm{app}}\right)$ in the polymerization of pMeSt, St and pClSt were determined using the equation $\ln \left([\mathrm{M}]_{0} /[\mathrm{M}]\right)=k_{\mathrm{app}} t$ (reaction conditions: $[\mathrm{pMeSt}]_{0}=0.46 \mathrm{M}, \quad\left[\mathrm{SnCl}_{4}\right]_{0}=5.0 \mathrm{~mm}$ for pMeSt; $\left[\mathrm{St}_{0}=0.52 \mathrm{M}, \quad\left[\mathrm{SnCl}_{4}\right]_{0}=10 \mathrm{mM}\right.$ for St; $[\mathrm{pClSt}]_{0}=0.47 \mathrm{M}$, $\left[\mathrm{SnCl}_{4}\right]_{0}=10 \mathrm{mM}$ for pClSt; $[\mathrm{CEECl}]_{0}=4.0 \mathrm{mM},[\mathrm{DTBP}]=2.0 \mathrm{mM}$ in $\mathrm{CH}_{2} \mathrm{Cl}_{2}$ at $0{ }^{\circ} \mathrm{C}$ ). The calculated $k_{\text {app }}$ values were as follows: $7.1 \mathrm{~h}^{-1}$ (pMeSt), $4.5 \times 10^{-2} \mathrm{~h}^{-1}$ (St) and $2.8 \times 10^{-3} \mathrm{~h}^{-1} \quad$ (pClSt).) The polymerization behavior of St derivatives using $\mathrm{SnCl}_{4}$ in the presence or absence of additives in dichloromethane is summarized in Table 3. In cationic polymerization, weakly Lewis basic additives affect polymerization activities through the moderation of catalytic activity. ${ }^{12,13}$ Polymerization using $\mathrm{SnCl}_{4}$ in conjunction with DTBP proceeded via activation by $\mathrm{SnCl}_{4}$, which is a highly reactive catalyst that does not 
a

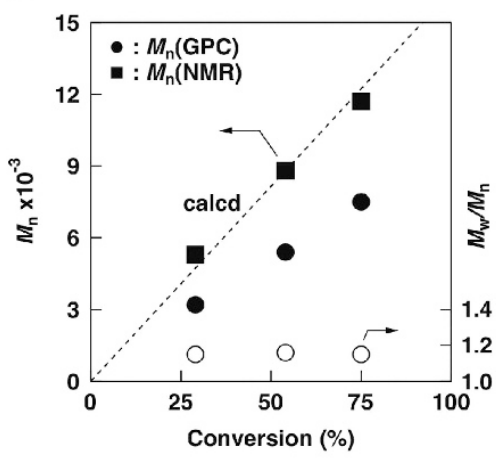

b

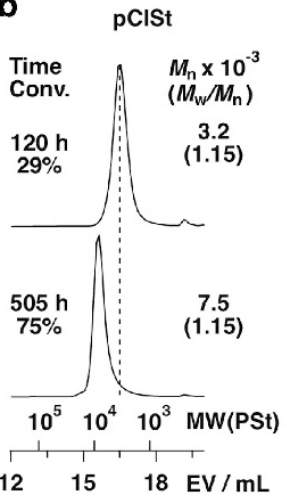

C

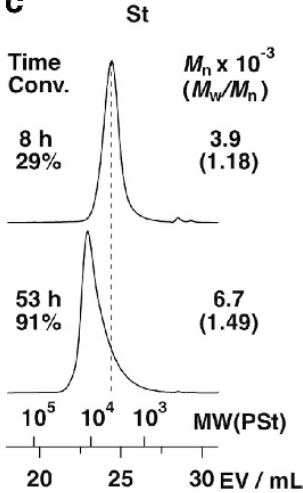

d

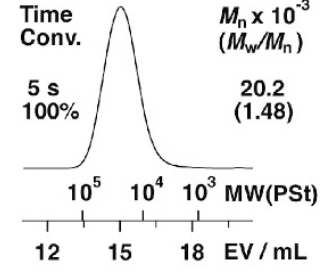

Figure 3 (a) $M_{\mathrm{n}}$ and $M_{\mathrm{w}} / M_{\mathrm{n}}$ for the polymerization of pCISt and MWD curves for (b) poly(pCISt)s, (c) poly(St)s and (d) poly(pMOS) obtained using SnCl ${ }_{4}$ in conjunction with DTBP: [monomer] $]_{0}=0.47 \mathrm{M}$ (for pClSt), $0.52 \mathrm{M}$ (for St) or $0.45 \mathrm{M}$ (for pMOS), [CEECl] $]_{0}=4.0 \mathrm{~mm}$, $\left[\mathrm{SnCl}_{4}\right]_{0}=5.0 \mathrm{~mm}$ (for pMOS) or $10 \mathrm{~mm}$ (for St and pClSt), [DTBP] $=2.0 \mathrm{~mm}$ in $\mathrm{CH}_{2} \mathrm{Cl}_{2}$ at $0^{\circ} \mathrm{C}$.

Table 3 Cationic polymerization behavior of $p$-substituted Sts using $\mathrm{SnCl}_{4}$ in dichloromethane

\begin{tabular}{llll}
\hline & DTBP $(2.0 \mathrm{~mm})$ & EtOAc $(1.0 \mathrm{~m})$ & None \\
\hline pMOS & $\begin{array}{l}\text { Uncontrolled } \\
\text { (High MW, broad MWD })\end{array}$ & $\begin{array}{l}\text { Well-controlled } \\
\left(M_{\mathrm{w}} / M_{\mathrm{n}}<1.3\right)^{\mathrm{a}}\end{array}$ & - \\
& Well-controlled & Controlled & Bimodal MWD \\
pMeSt & & \\
& $\left(M_{\mathrm{w}} / M_{\mathrm{n}}<1.2\right)$ & $(\text { Broad MWD })^{\mathrm{c}}$ & \\
St & Partly controlled & - & Bimodal MWD \\
& $($ side reaction $)$ & & Bimodal MWD \\
pCISt & Well-controlled & - & \\
& $\left(M_{\mathrm{w}} / M_{\mathrm{n}}<1.2\right)$ & & \\
\hline
\end{tabular}

a See Supplementary Figure S4A.

bThe polymerization of pMeSt using $\mathrm{SnCl}_{4}$ in conjunction with ethyl acetate in toluene proceeded in a controlled manner. (polymerization conditions: [pMeSt $]_{0}=0.46 \mathrm{M}$,

$[\mathrm{IBECl}]_{0}=4.0 \mathrm{~mm},\left[\mathrm{SnCl}_{4}\right]_{0}=10 \mathrm{~mm},[\mathrm{EtOAc}]=40 \mathrm{~mm}$ in toluene at $0{ }^{\circ} \mathrm{C}$. Conversion $=48 \%$ in

$\left.72 \mathrm{~h}, M_{\mathrm{n}}=5.6 \times 10^{3}, M_{\mathrm{w}} / M_{\mathrm{n}}=1.18\right)$.

'Entry 5 in Table 1 and Supplementary Figure S4B.

dRef. [32].

coordinate a Lewis base, and reversible deactivation by $\mathrm{SnCl}_{5}{ }^{-}$. Thus, this initiating system was efficient for polymerizing less reactive monomers, such as pMeSt, St and pClSt, but not for pMOS. As previously discussed, DTBP contributes to the adjustment of dormant-active equilibrium via the common-ion effect. In contrast, the initiating system with a large amount of ethyl acetate induced a controlled polymerization of pMOS (Supplementary Figure S4A) via the dormant-active equilibrium consisting of activation by $\mathrm{SnCl}_{4}(\mathrm{EtOAc})_{2}$ (after the liberation of EtOAc) and deactivation by $\mathrm{SnCl}_{5}(\mathrm{EtOAc})^{-} \cdot{ }^{19}$ In this case, the catalytic activity of $\mathrm{SnCl}_{4}$ is moderated through interaction with ethyl acetate. In addition, ethyl acetate contributes to the stabilization of propagating carbocation. These trends indicate that a suitable moderation of Lewis acidity of catalysts is indispensable for polymerizing St derivatives with a wide range of reactivity.

\section{Synthesis of the star-shaped poly(pMeSt)}

The initiating system consisting of $\mathrm{SnCl}_{4}$ and DTBP was examined next for the synthesis of core cross-linked star-shaped polymers. The star-shaped poly(pMeSt) was synthesized via the arm-first method (The combination of CEEA and $\mathrm{EtAlCl}_{2}$ was used instead of CEECl. ${ }^{34-36}$ This initiating system generates the $\mathrm{HCl}$ adduct of CEVE in situ. The propagation reaction proceeded by the catalysis of $\mathrm{SnCl}_{4}$ in a controlled manner (entry 6 in Table 1)). As shown in Scheme 3, a divinyl compound was added to the controlled arm polymerization solutions, as a cross-linking agent. Divinyl compounds with St moieties, BVPE and DVB, were used as cross-linking agents. Because BVPE has an alkyl group at p-positions of the vinyl groups, this linking agent exhibits reactivity similar to that of pMeSt. In the reaction with $\mathrm{DVB}$, a $\mathrm{SnCl}_{4}$ solution was added to accelerate the linking reaction. The reaction of poly $(\mathrm{pMeSt})$ propagating chains with BVPE smoothly proceeded to produce high-MW polymers with a $76 \%$ yield, as estimated from the area ratio on the MWD curve (Figure $4 \mathrm{a}$, bottom). The high-MW part was separated from the product via reprecipitation in $n$-hexane. As measured using GPC-MALS, the absolute $M_{\mathrm{w}}$ value of hexane-insoluble high-MW portion was larger than the $M_{\mathrm{w}}$ value determined by GPC with polystyrene calibration (entry 1 in Table 4). This indicated that the high-MW component was a star-shaped poly(pMeSt) with a BVPE cross-linked core.

DVB was also demonstrated to be efficient for the synthesis of starshaped polymers using the $\mathrm{SnCl}_{4} / \mathrm{DTBP}$ initiating system (Figure $4 \mathrm{~b}$, middle and bottom). However, the cross-linking reaction using DVB proceeded remarkably slower than the reaction using BVPE because DVB has a substantially lower reactivity relative to BVPE due to weaker electron-donation from the substituent (The chemical shift values of the $\beta$-carbon on the vinyl group of linking agents are as follows: 113.0 p.p.m. (BVPE), 113.9 p.p.m. (p-DVB) ${ }^{37}$ and 114.2 p.p. $\left.\mathrm{m} .(m-\mathrm{DVB}) .{ }^{37}\right)$ and/or shorter distance between the two vinyl groups. The ${ }^{1} \mathrm{H}$ NMR analysis of the star-shaped polymer and the residual arm, which were separated via reprecipitation in $n$-hexane, indicated that the unreacted vinyl groups remained in the star-shaped polymer and that the $\omega$-end functionality of the arm polymer was low (Supplementary Figure S5). In fact, similar amounts of poly(pMeSt) arm polymers remained for an even longer linking reaction time at room temperature, although the $M_{\mathrm{n}}$ values of the star-shaped polymer increased (entries 3 and 4 in Table 4). In addition, the peak of unreacted arm polymer did not shift to the higher-MW region after the addition of divinyl compound. These results suggest that the efficiency of the crossover reaction from poly(pMeSt) propagating cations to BVPE or DVB was not so high (72-76\%) under these conditions.

The obtained star-shaped poly(pMeSt) was utilized as a polymer-support for the supported catalyst. An insoluble cross-linked poly(St) produced through copolymerization of St and DVB is one of the representative polymer/organic supports for various chemical reactions. ${ }^{38-43}$ In a similar manner, $\mathrm{GaCl}_{3}$ was supported on the star-shaped polymer through the reaction of $\mathrm{GaCl}_{3}$ and the polymer in dichloromethane. The supported catalyst induced the 


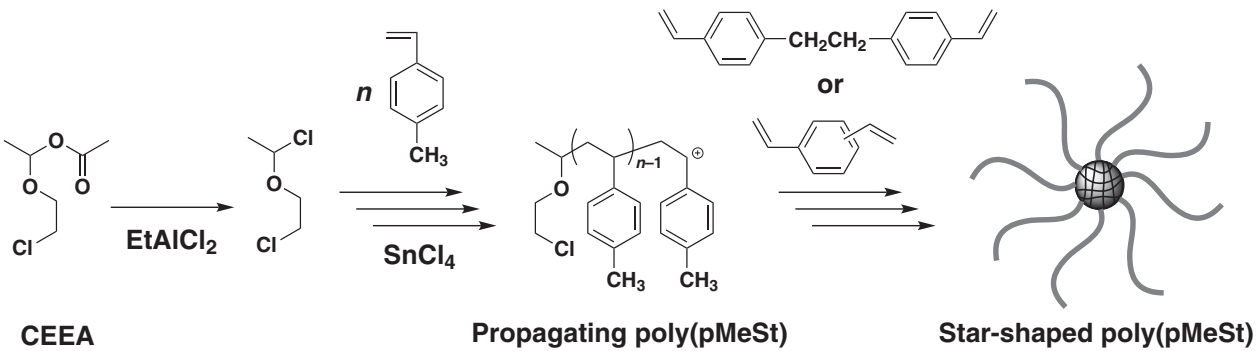

Scheme 3 Synthesis of star-shaped poly(pMeSt) via a linking reaction with the divinyl compound.
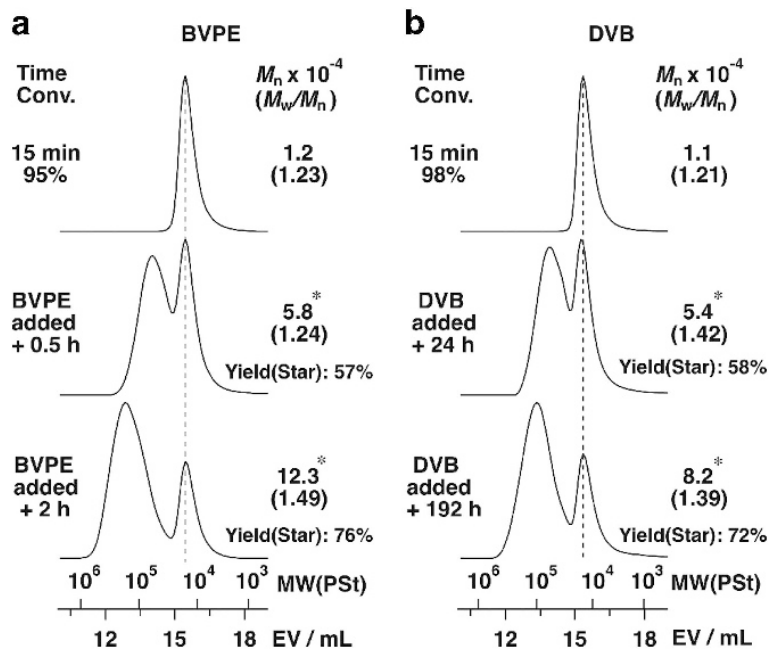

Figure 4 MWD curves for poly(pMeSt) arm (top) and star-shaped (middle and lower) polymers using BVPE (a) or DVB (b) as a cross-linking agent: $[\mathrm{pMeSt}]_{0}=0.46 \mathrm{~m}, \quad[\mathrm{CEEA}]_{0} /\left[\mathrm{EtAlCl}_{2}\right]_{0}=4.0 \mathrm{~mm} / 2.5 \mathrm{~mm}, \quad\left[\mathrm{SnCl}_{4}\right]_{0}=10 \mathrm{~mm}$, [DTBP] $=2.0 \mathrm{~mm}$ in $\mathrm{CH}_{2} \mathrm{Cl}_{2}$ at $0^{\circ} \mathrm{C}$ for arm polymerization. [divinyl compound $]_{\text {add }}=80 \mathrm{~mm}, \quad\left[\mathrm{SnCl}_{4}\right]_{\text {add }}=10 \mathrm{~mm}$ (for DVB) for star-shaped polymer synthesis. *For high-MW part.

controlled polymerization of IBVE in the presence of THF as an added base (see the Supporting Information for details; Supplementary Figure S6). The results indicate that the catalytic activity of $\mathrm{GaCl}_{3}$ in the core was maintained even after the exposure to water and air. The networked structure of the core and surrounding arm chains in the star-shaped poly(pMeSt) most likely protected $\mathrm{GaCl}_{3}$ from poisonous environments.

\section{CONCLUSION}

A well-controlled cationic polymerization of pMeSt was achieved using $\mathrm{SnCl}_{4}$ and $\mathrm{ZnCl}_{2}$ as catalysts in conjunction with DTBP. In addition, the combination of $\mathrm{SnCl}_{4}$ and DTBP was effective for controlled cationic polymerization of relatively less reactive St derivatives, such as St and pClSt. In addition, star-shaped poly(pMeSt)s were obtained via the arm-first method through the addition of a divinyl compound as a cross-linking agent. In contrast, metal trichlorides, such as $\mathrm{AlCl}_{3}$, $\mathrm{FeCl}_{3}$ and $\mathrm{GaCl}_{3}$, induced the uncontrolled polymerization of pMeSt. ${ }^{1} \mathrm{H}$ NMR analysis revealed the occurrence of side reactions, such as Friedel-Crafts reactions and/or $\beta$-proton elimination reactions. We expect this study to widen the scope of initiating systems for the controlled cationic polymerization of much less reactive monomers.
Table 4 Synthesis of star-shaped poly(pMeSt) by cationic polymerization $^{\mathrm{a}}$

\begin{tabular}{lccccccc}
$\begin{array}{c}\text { Entry } \\
\text { agent }\end{array}$ & $\begin{array}{c}\text { Linking } \\
\text { Time (h) }\end{array}$ & $\begin{array}{c}\text { Yield (star) } \\
(\%)^{\mathrm{c}}\end{array}$ & $\begin{array}{c}M_{n} \times 10^{-4} \\
(G P C)^{\mathrm{d}}\end{array}$ & $\begin{array}{c}M_{w} / M_{n} \\
(G P C)^{\mathrm{d}}\end{array}$ & $\begin{array}{c}M_{w} \times 10^{-4} \\
(G P C-M A L S)\end{array}$ & $N_{\text {arm }}{ }^{\mathrm{b}}$ \\
\hline 1 & BVPE & 2 & 76 & 11.6 & 1.58 & 94.7 & 49 \\
2 & DVB & 192 & 72 & 7.3 & 1.46 & 41.7 & 24 \\
3 & & 528 & 85 & 12.1 & 1.67 & - & - \\
$4^{\mathrm{e}}$ & 192 & 82 & 13.7 & 1.43 & 117 & 67 \\
\hline
\end{tabular}

${ }^{a}[\mathrm{pMeSt}]_{0}=0.46 \mathrm{~m},[\mathrm{CEEA}]_{0} /\left[\mathrm{EtAlCl}_{2}\right]_{0}=4.0 / 2.5 \mathrm{~mm},\left[\mathrm{SnCl}_{4}\right]_{0}=10 \mathrm{~mm},[\mathrm{DTBP}]=2.0 \mathrm{~mm}$ in $\mathrm{CH}_{2} \mathrm{Cl}_{2}$ at $0{ }^{\circ} \mathrm{C}$ for arm polymerization. [linking-agent $]_{\text {add }}=80 \mathrm{~mm},\left[\mathrm{SnCl}_{4}\right]_{\text {add }}=10 \mathrm{~mm}$ (for DVB) for star-shaped polymer synthesis.

${ }^{b}$ Average number of arms per molecule: $N_{\text {arm }}=$ [weight fraction of poly(pMeSt) arms] $\times$ $\left[M_{\mathrm{w}}(\mathrm{MALS})\right.$ of $\left.\operatorname{star}\right] /\left[M_{\mathrm{w}}(\mathrm{GPC})\right.$ of arm]. CDetermined by the peak area ratio of a high-MW part on the MWD curves of obtained polymers.

${ }^{\mathrm{d}}$ For insoluble portion in $n$-hexane.

eLinking reaction was conducted at room temperature.

\section{CONFLICT OF INTEREST}

The authors declare no conflict of interest.

\section{ACKNOWLEDGEMENTS}

This work was partially supported by the Grant-in-Aid for Scientific Research (No. 22107006) on Innovative Areas of 'Fusion Materials' (No. 2206) from MEXT and by the Grant-in-Aid for Scientific Research (B) (Nos. 24350059 and 26288063) and for Young Scientists (A) (No. 26708014) from JSPS.

1 Faust, R. \& Kennedy, J. P. Living carbocationic polymerization XVI. Living carbocationic polymerization of styrene. Polym. Bull. 19, 21-28 (1988).

2 Ishihama, Y., Sawamoto, M. \& Higashimura, T. Living cationic polymerization of styrene by the 1-phenylethyl chloride/tin tetrachloride initiating system in the presence of tetra- $n$-butylammonium chloride. Polym. Bull. 24, 201-206 (1990)

3 Kwon, O.-S., Kim, Y.-B., Kwon, S.-K., Choi, B.-S. \& Choi, S.-K. Living cationic polymerization of styrene by 1-chloroethylbenzene/tin(IV) chloride in chloroform. Makromol. Chem. 194, 251-257 (1993).

4 Lin, C.-H., Xiang, J. S. \& Matyjaszewski, K. "Living" cationic polymerization of styrene in the presence of tetrabutylammmonium salts. Macromolecules 26, 2785-2790 (1993).

5 Fodor, Z., Gyor, M., Wang, H.-C. \& Faust, R. Living cationic polymerization of styrene in the presence of proton trap. J. Macromol. Sci. Pure Appl. Chem. 30, 349-363 (1993).

6 Storey, R. F., Chisholm, B. J. \& Lee, Y. Synthesis and characterization of linear and three-arm star radial poly(styrene- $b$-isobutylene- $b$-styrene) block copolymers using blocked dicumyl chloride or tricumyl chloride/ $/ \mathrm{TiCl}_{4} /$ pyridine initiating system. Polymer 34, 4330-4335 (1993).

7 Kostjuk, S. V., Kapytsky, F. N., Mardykin, V. P., Gaponik, L. V. \& Antipin, L. M. Living cationic polymerization of styrene with 1-phenylethyl chloride/TiCl $/ \mathrm{Bu}_{2} \mathrm{O}$. Polym. Bull. 49, 251-256 (2002).

8 De, P., Sipos, L., Faust, R., Moreau, M., Charleux, B. \& Vairon, J.-P. Determination of the propagation rate constant in the carbocationic polymerization of 2,4,6-trimethylstyrene. Macromolecules 38, 41-46 (2005). 
9 Miyashita, K., Kamigaito, M., Sawamoto, M. \& Higashimura, T. End-functionalized polymers of styrene and $p$-methylstyrene by living cationic polymerization with functionalized initiators. Macromolecules 27, 1093-1098 (1994).

10 Oh, J.-M., Kang, S.-J., Kwon, O.-S. \& Choi, S.-K. Synthesis of ABA triblock copolymers of styrene and $p$-methylstyrene by living cationic polymerization using the bifunctional initiating system 1,4-bis(1-chloroethyl)benzene/ $\mathrm{SnCl}_{4}$ in the presence of 2,6-di-tert-butylpyridine. Macromolecules 28, 3015-3021 (1995).

11 De, P. \& Faust, R. Determination of the absolute rate constant of propagation for ion pairs in the cationic polymerization of p-methylstyrene. Macromolecules $\mathbf{3 8}$, 5498-5505 (2005).

12 Aoshima, S., Yoshida, T., Kanazawa, A. \& Kanaoka, S. New stage in living cationic polymerization: an array of effective Lewis acid catalysts and fast living polymerization in seconds. J. Polym. Sci. Part A: Polym. Chem. 45, 1801-1813 (2007).

13 Aoshima, S. \& Kanaoka, S. A renaissance in living cationic polymerization. Chem. Rev. 109, 5245-5287 (2009).

14 Kanaoka, S., Eika, Y., Sawamoto, M. \& Higashimura, T. Living cationic polymerization of $p$-chlorostyrene and related para-substituted styrene derivatives at room temperature. Macromolecules 29, 1778-1783 (1996).

15 De, P. \& Faust, R. Determination of the absolute rate constants of propagation for ion pairs in the carbocationic polymerization of p-chlorostyrene. Macromolecules 37, 9290-9294 (2004)

16 Aoshima, S., Segawa, Y. \& Okada, Y. Cationic polymerization of styrene in the presence of added base: living nature of the propagating species and synthesis of poly(vinyl alcohol)-graft-polystyrene. J. Polym. Sci. Part A: Polym. Chem. 39, 751-755 (2001).

17 Ashida, J., Yamamoto, H., Yonezumi, M., Kanaoka, S. \& Aoshima, S. Living cationic polymerization of styrene derivatives using $\mathrm{SnCl}_{4} / \mathrm{EtAlCl}_{2}$ in the presence of a Lewis base. Polym. Prep. (Am. Chem. Soc. Div. Polym. Chem.) 51 , 218-224 (2009)

18 Kanazawa, A., Kanaoka, S. \& Aoshima, S. Major progress in catalysts for living cationic polymerization of isobutyl vinyl ether: effectiveness of a variety of conventional metal halides. Macromolecules 42, 3965-3972 (2009).

19 Kanazawa, A., Shibutani, S., Yoshinari, N., Konno, T., Kanaoka, S. \& Aoshima, S. Structure effects of Lewis acids on the living cationic polymerization of $p$-methoxystyrene: distinct difference in polymerization behavior from vinyl ethers. Macromolecules 45, 7749-7757 (2012).

20 Higashimura, T., Kamigaito, M., Kato, M., Hasebe, T. \& Sawamoto, M. Living cationic polymerization of $\alpha$-methylstyrene initiated with a vinyl ether-hydrogen chloride adduct in conjunction with tin tetrabromide. Macromolecules 26, 2670-2673 (1993).

21 Aoshima, S. \& Higashimura, T. Living cationic polymerization of vinyl monomers by organoaluminum halides. 3. living polymerization of isobutyl vinyl ether by ethyldichloroaluminum in the presence of ester additives. Macromolecules 22 , 1009-1013 (1989)

22 Li, W.-H., Li, K., Stöver, H. D. H. \& Hamielec, A. E. High-yield synthesis and characterization of 1,2-bis( $p$-vinylphenyl)ethane. J. Polym. Sci. Part A: Polym. Chem. 32, 2023-2027 (1994).

23 Higashimura, T., Hiza, M. \& Hasegawa, H. Cationic oligomerization of methylstyrenes: effects of the methyl group and catalysts on product distributions. Macromolecules 12 , 1058-1061 (1979).

24 Sawamoto, M. \& Higashimura, T. Cationic oligomerization of unsaturated dimers of styrene and p-methylstyrene. Macromolecules 14, 467-471 (1981).

25 Storey, R. F., Curry, L. C. \& Hendry, L. K. Mechanistic role of Lewis bases and other additives in quasiliving carbocationic polymerization of isobutylene. Macromolecules 34, 5416-5432 (2001).

26 Katayama, H., Kamigaito, M. \& Sawamoto, M. In-situ direct analysis of the growing species by ${ }^{119}$ Sn NMR spectroscopy: living cationic polymerization of isobutyl vinyl ether with $\mathrm{HCl} / \mathrm{SnCl}_{4} / \mathrm{nBu}_{4} \mathrm{NCl}$. Macromolecules 31, 4703-4709 (1998).
27 Masure, M., Sigwalt, P. \& Sauvet, G. The cationic dimerization of 1,1-diphenylethylene, 4. Effects of a sterically hindered pyridine on the reaction initiated by aluminum chloride. Makromol. Chem. Rapid Commun. 4, 269-276 (1983).

28 Bennevault, V., Peruch, F. \& Deffieux, A. Influence of various proton traps on the bifunctional cationic polymerization of chloroethyl vinyl ether mediated by $\alpha$-iodo ether/zinc dichloride. Macromol. Chem. Phys. 197, 2603-2613 (1996).

29 Hashimoto, T., Iwata, T., Minami, A. \& Kodaira, T. Living cationic polymerization of vinyl ethers with carboxylic acid/tin tetrahalide initiating systems. I. new initiating systems based on acetic acid and selection of Lewis acid and basic additive leading to living polymers with low polydispersity. J. Polym. Sci. Part A: Polym. Chem. 36, 3173-3185 (1998).

30 Givehchi, M., Tardi, M., Polton, A. \& Sigwalt, P. Influence of 2,6-di-tert-4-methylpyridine on the polymerization of indene initiated with cumyl chloride/tin tetrachloride. Macromolecules 33, 9512-9517 (2000).

31 De, P. \& Faust, R. Living carbocationic polymerization of p-methoxystyrene using $p$-methoxystyrene hydrochloride/ $\mathrm{SnBr}_{4}$ initiating system: determination of the absolute rate constant of propagation for ion pairs. Macromolecules 37, 7930-7937 (2004).

32 Higashimura, T., Ishihama, Y. \& Sawamoto, M. Living cationic polymerization of styrene: new initiating systems based on added halide salts and the nature of the growing species. Macromolecules 26, 744-751 (1993).

33 Kamigaito, M., Maeda, Y., Sawamoto, M. \& Higashimura, T. Living cationic polymerization of isobutyl vinyl ether by hydrogen chloride/Lewis acid initiating systems in the presence of salts: in-situ direct NMR analysis of the growing species. Macromolecules 26, 1643-1649 (1993).

34 Yoshida, T., Kanazawa, A., Kanaoka, S. \& Aoshima, S. Instant living cationic polymerization using $\mathrm{SnCl}_{4} / \mathrm{EtAlCl}_{2}$ with a weak Lewis base: ultrafast polymerization in seconds. J. Polym. Sci. Part A: Polym. Chem. 43, 4288-4291 (2005).

35 Kanaoka, S., Yamada, M., Ashida, J., Kanazawa, A. \& Aoshima, S. Domino synthesis of star-shaped polymers based on monomer selective living cationic polymerization: highly controlled star polymer formation. J. Polym. Sci. Part A: Polym. Chem. 50, 4594-4598 (2012).

36 Shinke, Y., Kanazawa, A., Kanaoka, S. \& Aoshima, S. Living cationic polymerization of vinylnaphthalene derivatives. J. Polym. Sci. Part A: Polym. Chem. 51, 4828-4834 (2013)

37 Tanaka, S., Matsumoto, M., Goseki, R., Ishizone, T. \& Hirao, A. Living anionic polymerization of 1,4-divinylbenzene and its isomers. Macromolecules 46, 146-154 (2013).

38 McNamara, C. A., Dixon, M. J. \& Bradley, M. Recoverable catalysts and reagents using recyclable polystyrene-based supports. Chem. Rev. 102, 3275-3300 (2002)

$39 \mathrm{Lu}$, J. \& Toy, P. H. Organic polymer supports for synthesis and for reagent and catalyst immobilization. Chem. Rev. 109, 815-838 (2009).

40 Kobayashi, S. \& Nagayama, S. A microencapsulated Lewis acid. A new type of polymersupported Lewis acid catalyst of wide utility in organic synthesis. J. Am. Chem. Soc. 120, 2985-2986 (1998).

41 Neckers, D. C., Kooistra, D. A. \& Green, G. W. Polymer-protected reagents. Polystyrenealuminum chloride. J. Am. Chem. Soc. 94, 9284-9285 (1972).

42 Tamami, B. \& Borujeny, K. P. Chemoselective tetrahydropyranylation of alcohols and phenols using polystyrene supported aluminium chloride as a catalyst. Tetrahedron Lett. 45, 715-718 (2004)

43 Ran, R., Fu, D. \& Wang, Q. Polymer-supported Lewis acid catalysts. VII. Polystyrenebonded Ti(IV) chloride catalysts. J. Polym. Sci. Part A: Polym. Chem. 31, 2915-2921 (1993)

Supplementary Information accompanies the paper on Polymer Journal website (http://www.nature.com/pj). 